\title{
Íleo biliar: Reporte de un caso de fístula colecistoduodenal asociada a hernia inguinal izquierda
}

\author{
Dres. Natalia Negretti', Sebastián Giménez', Gustavo Raichholz², José Luis Sañudo².
}

1. Médico residente Diagnóstico por Imágenes Junín, Santa Fé, Argentina. nataliacnegretti@gmail.com

2. Médico especialista en diagnóstico por imágenes. Argentina.

\section{Gallstone ileus: A case report of cholecystoduodenal fistula associated with leftinguinal hernia}

Astract. Biliary ileus, first described by Thomas Bartholin in the year 1654, is a rare cause of mechanical ileus (small bowel obstruction) (1-3\% in patients younger than 65 years), increasing significantly from that age (25\%). The necessary condition for this pathology is the presence of a fistula between the gallbladder and the gastrointestinal tract. Simple abdominal $X$-ray and ultrasonography are widely available and of relatively low cost, together presenting a sensitivity of $74 \%$ when they show the classic signs of Rigler's triad (pneumobilia, ectopic gallstone and dilated loops of small intestine), but computed tomography of the abdomen is considered the gold standard, with a sensitivity and specificity higher than $90 \%$. The aim of this article is to present a case of radiological diagnosis of biliary ileus in a patient with vesicular lithiasis + cholecystoduodenal fistula, associated with inguinal hernia on the left.

Keywords: Biliary ileus, Cholelithiasis, Cholecystoduodenal fistula, Acute abdomen, Computed tomography, Inguinal hernia.

Resumen. El íleo biliar, descrito por primera vez por Thomas Bartholin en el año 1654, constituye una causa poco frecuente de íleo mecánico (1-3\% en menores de 65 años) aumentando significativamente a partir de esa edad (25\%).

La condición necesaria para esta patología es la presencia de una fístula entre la vesícula biliar y el tracto gastrointestinal. La radiografía simple de abdomen y la ecografía son de amplia disponibilidad y coste relativamente bajo, presentando en conjunto una sensibilidad del $74 \%$ cuando manifiestan los signos clásicos de la tríada de Rigler (neumobilia, lito biliar ectópico y dilatación de asas de intestino delgado), pero se considera que la tomografía computada de abdomen es el gold standard, con una sensibilidad y especificidad superiores al $90 \%$.

El objetivo de este artículo es presentar un caso de diagnóstico radiológico de íleo biliar en un paciente con litiasis vesicular + fístula colecistoduodenal asociadas a hernia inguinal izquierda.

Palabras clave: Íleo biliar, Colelitiasis, Fístula colecistoduodenal, Abdomen agudo, Tomografía computada, Hernia inguinal.

Negretti N., et al. Íleo biliar: Reporte de un caso de fístula colecistoduodenal asociada a hernia inguinal izquierda Rev Chil Radiol 2017; 23(1): 20-24.

Correspondencia: Natalia Negretti / nataliacnegretti@gmail.com

Trabajo recibido el 21 del noviembre de 2016. Aceptado para publicación el 17 demarzo de 2017.

\section{Introducción}

El abdomen agudo es un motivo de consulta frecuente en el servicio de urgencias y la importancia de su reconocimiento radica en reconocer aquellos pacientes que se beneficiarán con tratamiento médico de los que requerirán una cirugía. Su diagnóstico etiológico puede resultar difícil, siendo la oclusión intestinal uno de los más frecuentes.

Existen múltiples causas de obstrucción, entre ellas las hernias externas y, en menor grado, el íleo biliar. Este último es una entidad de elevada morbimortalidad dado que la mayoría de los pacientes son de edad avanzada y en ellos es común la presencia de enfermedades concomitantes, por lo que es preciso su diagnóstico temprano, llegando a ser pre-operatorio en menos del $50 \%$ de los casos.

El objetivo de este artículo es presentar un caso de diagnóstico radiológico de íleo biliar en un paciente con litiasis vesicular + fístula colecistoduodenal asociadas a hernia inguinal izquierda. 


\section{Presentación del caso}

Paciente masculino, de 83 años, ex tabaquista. Antecedentes médicos: hipertrofia prostática benigna, glaucoma, hernia inguinal y litiasis vesicular.

Ingresa al servicio de guardia por cuadro de 6 meses de evolución caracterizado por dispepsia y epigastralgia, que cede con tratamiento sintomático. Refiere pérdida de $10 \mathrm{Kg}$. de peso en los últimos meses. Al momento de la consulta presenta intolerancia oral y aumento de la intensidad de la epigastralgia.

Al examen físico presenta abdomen distendido, timpánico a la percusión, doloroso a la palpación superficial y profunda, sin contractura muscular ni reacción peritoneal. Ruidos hidroaéreos aumentados.

Se solicitan exámenes complementarios. Analítica de sangre: Urea 0,86 - Creatinina 1,93. Resto de los parámetros dentro de valores normales.

La radiografía directa de abdomen mostró dilatación de asas de intestino delgado.

Ante la sospecha clínico-radiológica de íleo, se procede a la realización de tomografía computada de abdomen y pelvis con inyección de contraste endovenoso no iónico, en la cual se evidencia aumento difuso del calibre de las asas yeyuno-ileales (Figura 1), visualizando el sitio de transición en topografía de la región inguinal izquierda (Figura 2 ) donde se observa saco herniario con asa ileal en su interior, la cual presenta en su luz imagen calcificada parcialmente de 3,2 x 1,6 cm de diámetro, compatible con litiasis (Íleo biliar) (Figuras $3 \mathrm{a}$ y b). También se observa dentro del saco herniario leve cantidad de líquido libre y asa del colon sigmoides. La vesícula biliar se encuentra colapsada, de paredes engrosadas en forma difusa, mostrando en su interior contenido aéreo (Figura 4). Se logra identificar fístula bilio-digestiva que comunica la vesícula biliar con la primera porción duodenal (Figura 5).

Se procede a la interconsulta con el servicio de cirugía, donde se decide realizar hernioplastia inguinal izquierda con colocación de malla + resección y anastomosis intestinal por íleo biliar (Figura 6), decidiendo el cierre de la fístula en segundo tiempo.

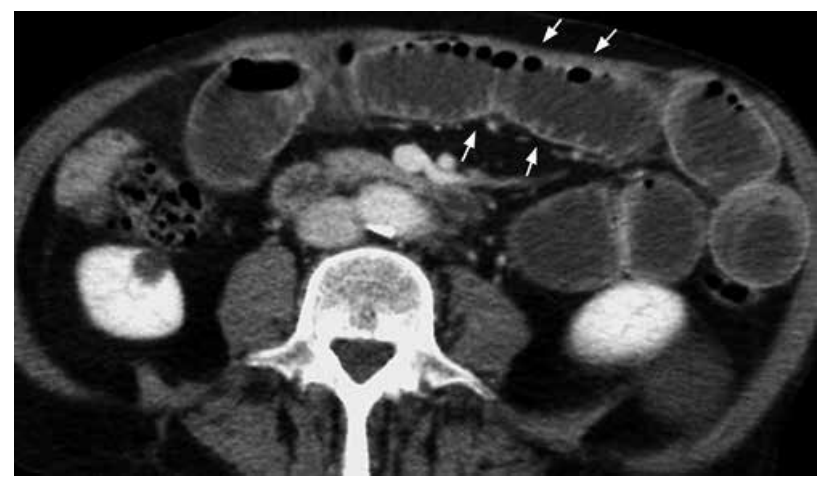

Figura 1. TC de abdomen con contraste, corte axial. Se visualiza dilatación difusa de asas yeyuno-ileales (flechas blancas).

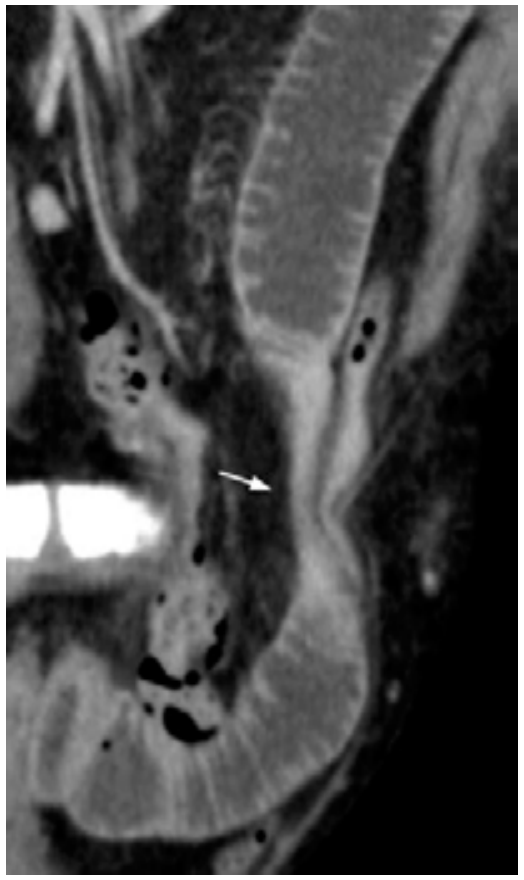

Figura 2. TC de abdomen con contraste, corte coronal, mostrando el sitio de transición en topografía de la región inguinal izquierda (flecha blanca).

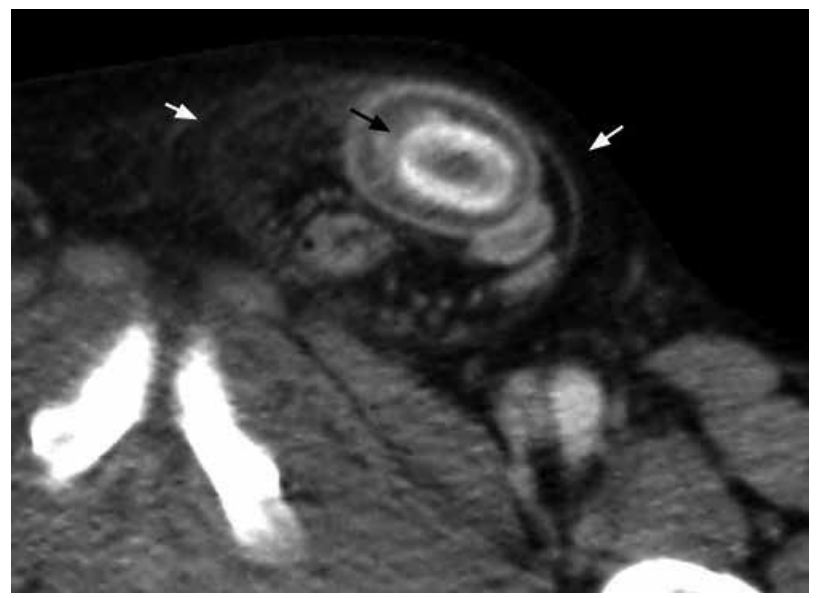

Figura 3. TC abdomen con contraste, corte axial (a) y sagital (b). Se visualiza hernia inguinal izquierda de tipo indirecta con protrusión de asa ileal (flechas blancas), identificándose en su luz imagen calcificada compatible con litiasis (flecha negra), siendo esta última la causa de la obstrucción mecánica.

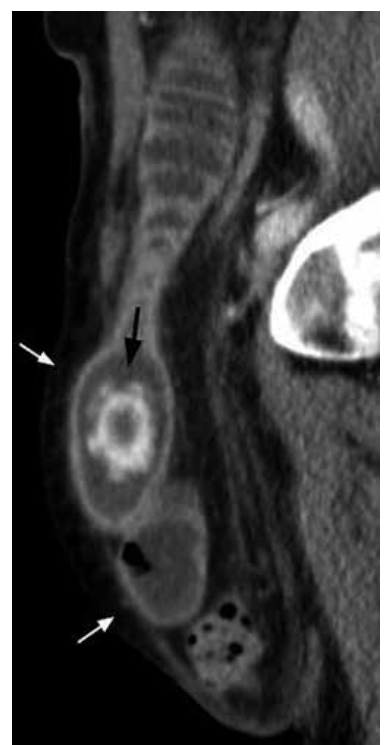




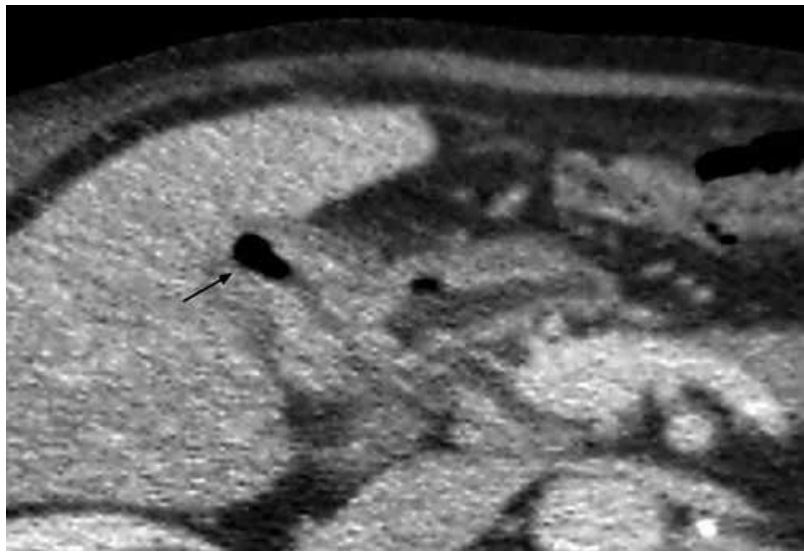

Figura 4. TC abdomen con contraste, corte axial. Nótese vesícula biliar colapsada, con engrosamiento parietal difuso, mostrando en su interior contenido aéreo (flecha negra).

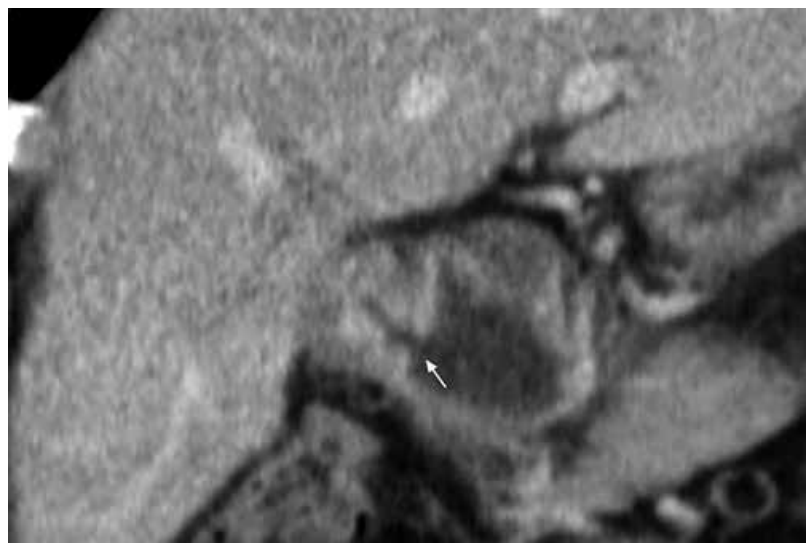

Figura 5. Se identifica fístula bilio-digestiva (flecha blanca) que comunica la vesícula biliar con la primera porción duodenal.

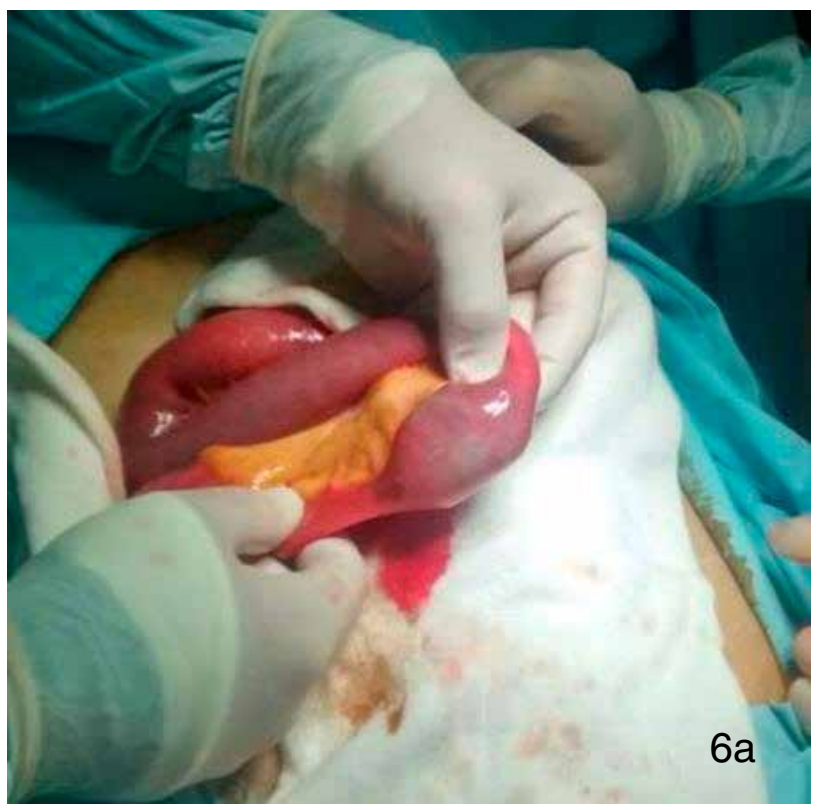

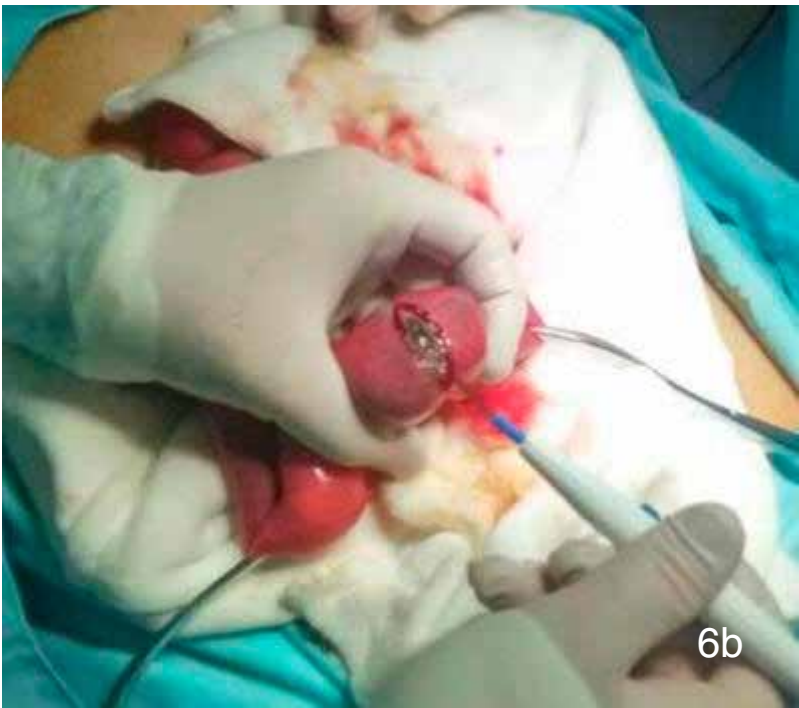

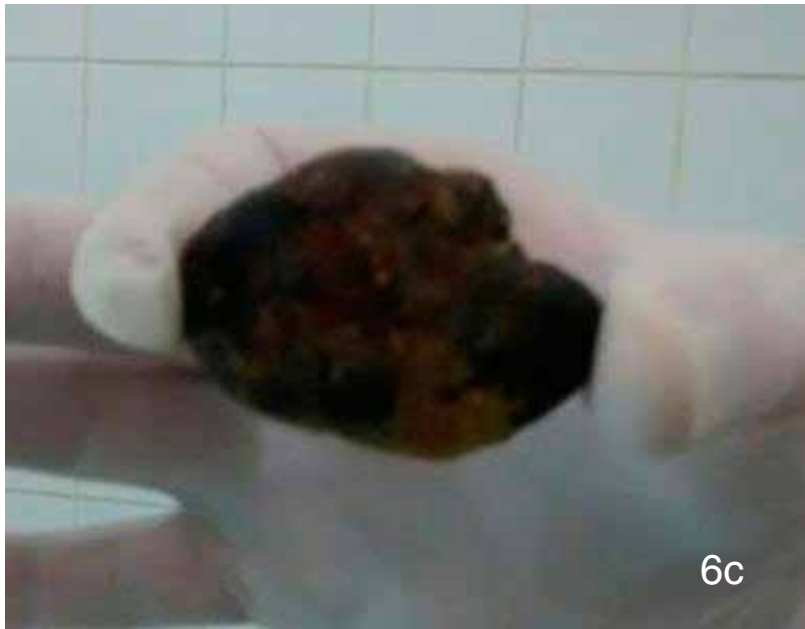

Figura 6. Extracción del lito a través de enterotomía.

\section{Discusión}

La obstrucción intestinal es un cuadro clínico común que se produce por obstrucción mecánica o funcional del mismo, impidiendo el tránsito normal de su contenido ${ }^{1}$.Es responsable de aproximadamente el $20 \%$ de los ingresos quirúrgicos.

El intestino delgado es el sitio de obstrucción en el $60-80 \%$ de los casos, siendo las bridas o adherencias peritoneales las causa más frecuente $(49 \%)$, seguida por las neoplasias $(16 \%)$ y las hernias $(15 \%)^{2}$.

El íleo biliar constituye una causa poco frecuente de íleo mecánico (1-3\% en menores de 65 años) aumentando significativamente en mayores de 65 años $(25 \%)^{3}$. Afecta predominantemente al sexo femenino.

La patología fue descripta por primera vez por Thomas Bartholin en el año 1654, en un estudio post mortem ${ }^{3}$.

La condición necesaria para esta patología es la presencia de una fístula entre la vesícula biliar y el 
tracto gastrointestinal; pero sólo 1-15\% de las fístulas bilio-digestivas producen íleo biliar.

El antecedente de enfermedad biliar, particularmente colecistitis crónica litiásica, predispone a la inflamación crónica de la vesícula biliar con la consecuente isquemia y erosión del cálculo a través de la pared vesicular, formando una fístula colecisto-entérica ${ }^{3,4}$, siendo la más frecuente la colecisto-duodenal (65$77 \%)$ seguida de la colecisto-cólica (10-25\%) y colecisto-gástrica (5\%), esta última ocluye la salida gástrica a nivel del píloro y se conoce como Síndrome de Bouveret ${ }^{5}$.

El tercio medio y distal del íleon son los principales sitios de obstrucción debido al menor diámetro de su luz y a la disminución de la actividad peristáltica a este nivel. La impactación o no del lito depende de dos factores: que exista otra causa de estenosis intestinal y del diámetro del cálculo ${ }^{4}$. Se estima que para que un lito ocasione una obstrucción intestinal debe medir aproximadamente $2,5 \mathrm{~cm}$, salvo que exista otra causa de estenosis intestinal ${ }^{5}$.

El cuadro clínico inespecífico de dolor abdominal y vómitos, de presentación insidiosa, dificulta el diagnóstico; siendo postoperatorio en un $57 \%$ de casos $^{4}$.

La radiografía convencional es el método inicial de exploración radiológica ${ }^{2}$, debido a su amplia disponibilidad y su coste relativamente bajo, sin embargo, sólo son diagnósticas en el $50-60 \%$ de los casos $^{1}$, debido a que aporta información inespecífica, excepto en los casos en que presenta los signos clásicos de la tríada de Rigler que incluyen neumobilia, lito biliar ectópico y dilatación de asas de intestino delgado. La presencia de dos de estos signos es suficiente para realizar el diagnóstico ${ }^{3,4}$.

La ultrasonografía abdominal es de utilidad acotada $^{3}$. Su principal limitación es la interposición de asas intestinales llenas de gas ${ }^{1}$, pero aumenta la sensibilidad de la radiografía simple de abdomen hasta un $74 \%$ con el hallazgo de neumobilia y la visualización del lito en la luz intestinal ${ }^{3}$.

La tomografía computada de abdomen se considera el gold standard para el diagnóstico de íleo biliar, con una sensibilidad del $90-96 \%$ y una especificidad del $96 \%{ }^{1}$, pudiéndose identificar además de la tríada de Rigler, la presencia de colecistitis crónica y fístula ${ }^{3}$. En general no se requiere la administración de contraste oral debido a que el contenido intraluminal retenido sirve como agente de contraste negativo natural.

Los criterios para determinar si el sitio de la oclusión es en intestino delgado son la presencia de asas dilatadas $>2,5 \mathrm{~cm}$ (de pared externa a pared externa), visualización de una zona de transición entre asas proximales distendidas y distales colapsadas. El "signo de las heces en el intestino delgado" consiste en la identificación de material particulado intraluminal en un asa dilatada proximal a la obstrucción; si bien su prevalencia es baja (7-8\%), cuando está presente es un complemento para identificar el sitio de transición'.

El tratamiento del íleo biliar es urgente y sólo se retrasa para compensar hidroelectrolíticamente al paciente.

La terapia de elección es la laparotomía y enterolitotomía, explorando minuciosamente la totalidad del intestino para descartar la presencia de más litos; también comprobar vesícula biliar y la fístula para descartar fuga, absceso local o litos adicionales.

Un motivo de controversia es la elección del mejor abordaje quirúrgico. Se cuestiona si se realiza el tratamiento definitivo de la fístula bilio-entérica, teniendo en cuenta que la mayoría cierran espontáneamente y sólo se observa $4,7 \%$ de recurrencia de íleo biliar. Otro factor a considerar es la necesidad de colecistectomía en pacientes asintomáticos.

Clásicamente se recomienda que en casos de urgencia y teniendo en cuenta que la mayoría de los pacientes son mayores de 75 años, el principal objetivo es tratar la obstrucción intestinal y si existe sintomatología, la vía biliar puede extraerse en otro tiempo en forma selectiva ${ }^{4}$.

La mortalidad de $12-20 \%$ se debe fundamentalmente al retraso en su diagnóstico preoperatorio y a la edad avanzada de los pacientes, las condiciones clínicas y la alta incidencia de comorbilidades en este grupo etario ${ }^{3}$.

\section{Conclusión}

El íleo biliar es una causa poco frecuente de obstrucción intestinal, pero su incidencia aumenta con la edad. Su principal desafío es su diagnóstico precoz, ya que en la mayoría de los casos se realiza durante una laparotomía exploradora, aumentando el riesgo de complicaciones en un grupo etario que de por sí presenta una elevada tasa de mortalidad.

El uso combinado de la radiografía directa de abdomen con la ecografía aumenta el diagnóstico preoperatorio en pacientes en los que el cuadro clínico se solapa con las enfermedades concomitantes que suelen presentarse a esta edad; pero se considera que la tomografía computada de abdomen es el gold standard, presentando una sensibilidad y especificidad superiores al $90 \%$, cuando a los criterios radiológicos clásicos de la tríada de Rigler (que incluyen neumobilia, lito biliar ectópico y dilatación de asas de intestino delgado), se suman la presencia de colecistitis crónica y fístula bilio-digestiva.

\section{Bibliografía}

1. Silva AC, Pimenta M, Guimaraes LS. Small Bowel Obstruction: What to Look for. Radiographics 2009; 29: 423-439.

2. Maglinte DDT, Kelvin FM, Rowe MG, Bender GN, Rouch DM. Small-Bowel Obstruction: Optimizing Radiologic Investigation and Nonsurgical Management. Radiology 2001; 218: 39-46.

3. Mancilla Ulloa FJ, Rayas Ruiz D. Íleo biliar: reporte de 
un caso y revisión de la literatura. Cir Gen 2014; 36(2): 121-125

4. Salazar-Lozano C, Rocha-Guevara ER, Vargas-Gismondi A, de La Fuente-Lira M, de Obaldía-Zeledón RE, Cordero-Vargas $\mathrm{C}$. Íleo biliar y fístula colecistoduodenal.
Informe de un caso. Cir Ciruj 2006; 74: 199-203.

5. Rojas-Rojas DJ, Martínez-Ordaz JL, Romero-Hernández T. Íleo biliar. Experiencia de 10 años. Serie de casos. Cir Cir 2012; 80: 228-23. 